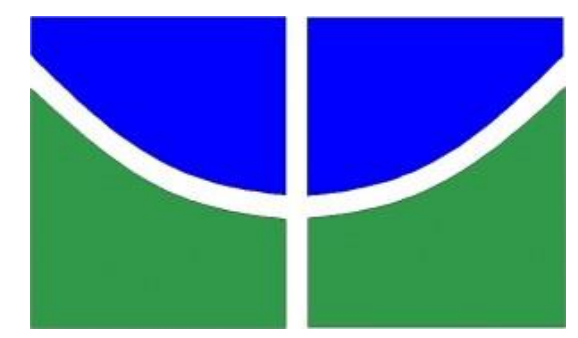

UNIVERSIDADE DE BRASÍLIA

Faculdade de Ciências da Saúde

Departamento de Enfermagem

Matheus Fernandes Santos Costa

INFECÇÃO HOSPITALAR EM PESSOAS IDOSAS EM UM HOSPITAL UNIVERSITÁRIO DO DISTRITO FEDERAL

BRASÍLIA - DF

2017 
Matheus Fernandes Santos Costa

INFECÇÃO HOSPITALAR EM PESSOAS IDOSAS EM UM HOSPITAL UNIVERSITÁRIO DO DISTRITO FEDERAL

Trabalho de Conclusão de Curso (TCC) como prérequisito para obtenção do título de bacharel em Enfermagem, pelo Departamento de Enfermagem da Faculdade de Ciências da Saúde da Universidade de Brasília.

Orientadora: Prof ${ }^{\mathrm{a}} \mathrm{Dr}^{\mathrm{a}}$ Andrea Mathes Faustino.

BRASÍLIA - DF 
Matheus Fernandes Santos Costa

\title{
INFECÇÃO HOSPITALAR EM PESSOAS IDOSAS EM UM HOSPITAL UNIVERSITÁRIO DO DISTRITO FEDERAL
}

Brasília,

\section{COMISSÃO EXAMINADORA}

\author{
Profa. Dra. Andréa Mathes Faustino \\ Faculdade de Ciências da Saúde / Departamento de Enfermagem \\ Universidade de Brasília-UnB \\ Orientadora - Presidente da Banca
}

Profa. Dra. Keila Cristianne Trindade da Cruz

Faculdade de Ciências da Saúde / Departamento de Enfermagem Universidade de Brasília-UnB Membro Efetivo da Banca

Profa. Dra. Carla Targino Bruno dos Santos

Faculdade de Ciências da Saúde / Departamento de Enfermagem Universidade de Brasília-UnB Membro Efetivo da Banca

Profa. Dra. Dayde Lane Mendonça da Silva Faculdade de Ciências da Saúde / Departamento de Farmácia Universidade de Brasília-UnB Membro Suplente da Banca 


\section{AGRADECIMENTOS}

Agradeço a Deus por ter me concedido saúde, discernimento, fé e sabedoria para saber como agir de forma a superar as dificuldades surgidas ao longo dessa etapa, permitindo a realização e conclusão desse trabalho que tanto me ensinou.

Aos meus pais, Marcos e Ruth, pelo amor, dedicação, por sempre acreditarem no meu potencial, com incentivo e apoio na tomada de decisões e busca daquilo que almejo.

A minha irmã, pelo apoio e carinho.

A esta Universidade pelo sonho concretizado, pelas experiências vivenciadas e ao corpo docente, pelo aprendizado e exemplo para a construção do profissional que vislumbro ser. Em especial à minha orientadora Andréa Mathes Faustino, pelo suporte em tudo que lhe coube, pelas correções, paciência, dedicação, incentivos e atenção.

A minha noiva Rainah Ramos que se fez presente durante todo o processo, pela ajuda e incentivo ao decorrer do trabalho.

A todos que de alguma maneira contribuíram para que eu chegasse até aqui. 
Deus não escolhe os capacitados, capacita os escolhidos.

Fazer ou não fazer algo só depende de nossa vontade e perseverança.

Albert Einstein 
SUMARIO

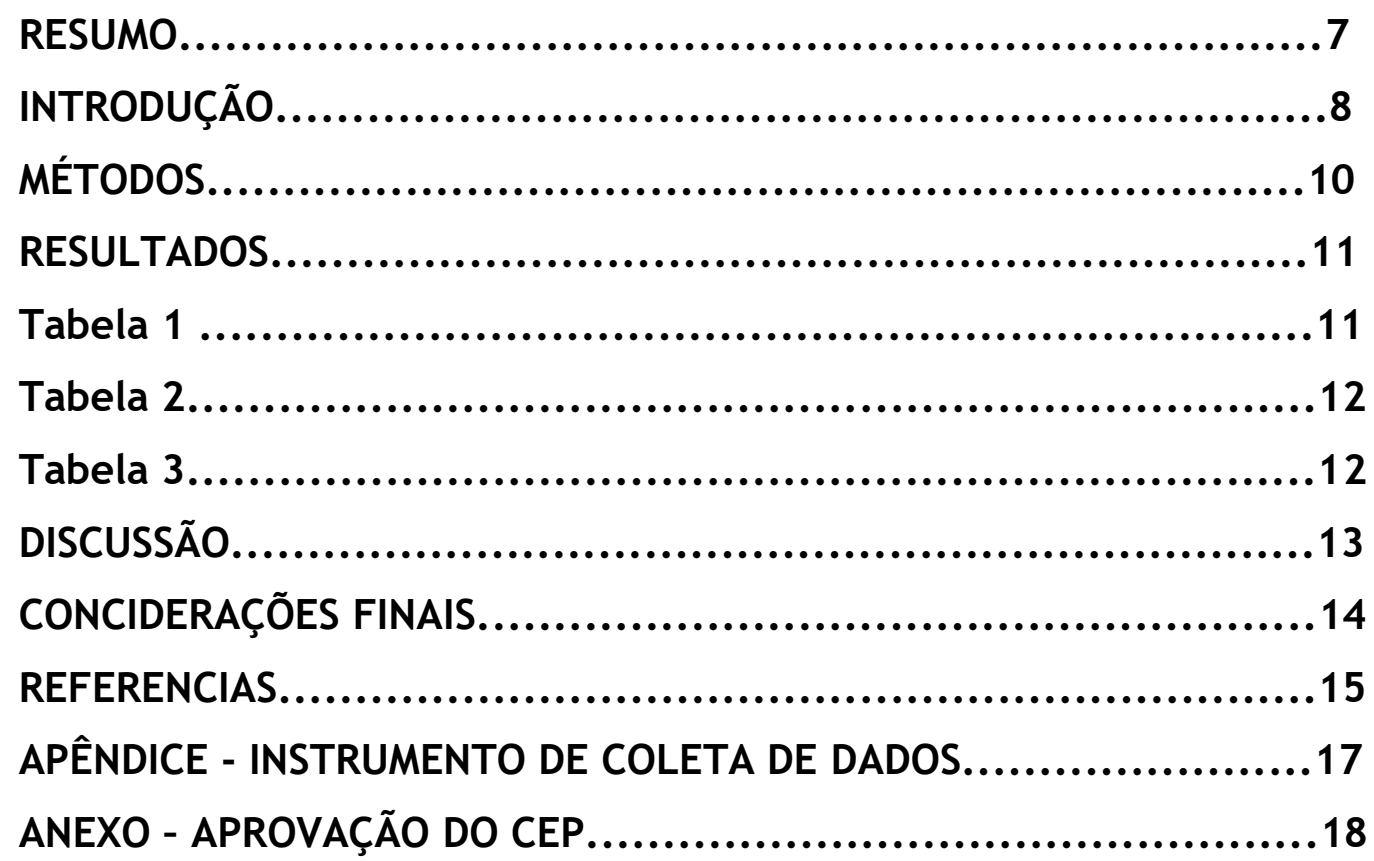




\section{INFECÇÃO HOSPITALAR EM PESSOAS IDOSAS EM UM HOSPITAL UNIVERSITÁRIO DO DISTRITO FEDERAL}

\section{Matheus Fernandes Santos Costa $^{1}$, Andréa Mathes Faustino ${ }^{2}$}

${ }^{1}$ Discente do curso de Enfermagem Bacharel, Faculdade de Ciências da Saúde, Campus Darcy Ribeiro, Universidade de Brasília (UnB), Brasília, DF, Brasil.

2Enfermeira Especialista em Gerontologia Docente no Departamento de Enfermagem, Faculdade de Ciências da Saúde, Campus Darcy Ribeiro, Universidade de Brasília (UnB), Brasília, DF, Brasil,

RESUMO: Trata-se de um estudo epidemiológico, de caráter descritivo correlacional, retrospectivo, com análise quantitativa de prontuários. A pesquisa foi realizada em um hospital universitário do Distrito Federal, no Serviço de Arquivo Médico (SAME). Consideramos a amostragem não-probabilística, do tipo por conveniência. Como critério de inclusão foram considerados os seguintes aspectos: ser prontuário de pessoas idosas, ou seja, o paciente deveria ter 60 anos ou mais, ter ficado internado na unidade de internação da clínica médica em algum período dos anos de 2014 e 2015. A amostra constitui-se por 102 prontuários no ano 2014 e 103 no ano de 2015, totalizando 205 prontuários, referentes às internações de pacientes na Clínica Médica, sendo destes 58,8\% ( $n=57)$ no ano de 2014 e $34,9 \%(n=36)$ no ano de 2015 , no total $45,3 \%(n=95)$ de pessoas com 60 anos ou mais. A taxa de IH no período de internação para estes idosos foi no total de $21,5 \%$. 0 que nos chamou a atenção foram as características extrínsecas e intrínsecas do paciente que podem estar relacionadas com o surgimento da $\mathrm{IH}$, a qual destacamos o período de tempo elevado de internação (média de 7 dias a 34 dias), a idade (mínima de 60 anos) e os diagnósticos médicos. Os indicadores analisados durante a pesquisa podem favorecer uma análise que pode estabelecer ações de prevenção de IH por parte de todos os profissionais de saúde envolvidos no cuidado aos pacientes e, principalmente, aos próprios idosos, dos quais devem ser considerados todos os aspectos do processo de envelhecimento senil $\mathrm{e}$ senescente.

*Estudio epidemiológico, de carácter descriptivo correlacional, retrospectivo, con análisis cuantitativa de los registros de los pacientes. La población del estudio fue compuesta por todos los registros de pacientes ancianos admitidos en la Unidad de Clínica Médica durante los años de 2014 y 2015, así, la amuestra fue de conveniencia, o sea, todos los ancianos de estos periodos fueron incluidos. La presente investigación fue realizada en un hospital universitario de Brasilia, ubicado en el Distrito Federal, en el Servicio de Archivo Médico (SAME). Los criterios de inclusión fueron: ser registros de ancianos de ambos sexos, admitidos en la Unidad de Clínica Médica, durante los años de 2014 y 2015. La amuestra se constituye por 102 registros en el año 2014 y 103 en año de 2015, totalizando 205 registros, referentes a las internaciones de pacientes en la Clínica Médica, siendo de estos $58,8 \%(n=57)$ en el año de 2014 y $34,9 \%(n=36)$ en el año de 2015, totalizando 45,3\% $(\mathrm{n}=95)$ de personas con 60 años o más. La tasa de IH no periodo de internación para estos ancianos fue un total de $21,5 \%$. Lo que nos llama atención fueron las características extrínsecas e intrínsecas del paciente que pueden estar relacionadas con el surgimiento de 
la IH, la cual destacamos el periodo de internación (promedio de 7 a 34 días), la edad (mínima de 60 años) y los diagnósticos médicos. Los indicadores analizados durante la investigación pueden favorecer un análisis que puede establecer acciones de prevención de IH por parte de todos los profesionales de salud envueltos en el cuidado a los pacientes y, principalmente a los ancianos, los cuales deben ser considerados los aspectos del proceso de envejecimiento senil y senescente.

DESCRITORES: Infecção Hospitalar; Hospital Infection; Infección hospitalaria; Idoso; Aged; Anciano; Epidemiologia; Epidemiology; Epidemiología

\section{INTRODUÇÃO}

$\mathrm{Na}$ Idade Média iniciaram-se as suspeitas de que algo "sólido" pudesse transmitir doenças de um indivíduo a outro. Foi em 1546 que Francastorius, defendeu a teoria de que certas patologias se transmitiam através de corpúsculos que ele denominou de semente da moléstia (seminária prima) e essas sementes transitavam de um corpo para outro através do contato direto ou através de roupas e objetos. ${ }^{1}$

Em 1863, a enfermeira Florence Nightingale descreveu procedimentos de cuidados relacionados aos pacientes e ao ambiente, com a finalidade de diminuir os riscos da Infecção Hospitalar (IH). Florence solicitava que as enfermeiras mantivessem um sistema de relato dos óbitos hospitalares com o objetivo de avaliar o serviço. ${ }^{2}$

Segundo a Portaria n. 2.616/1998 (BRASIL, 1998), IH é toda aquela adquirida durante a internação, normalmente provocada pela microbiota bacteriana humana que, em decorrência da doença, dos procedimentos invasivos e do contato com a microbiota hospitalar, se desequilibra com os mecanismos de defesa do organismo. ${ }^{3}$

Tendo em vista as principais IH endêmicas nas pessoas idosas; a infecção do trato urinário é na maioria das vezes a mais comum, causado principalmente pela bactéria Escherichia coli seguida de outras enterobactérias, Pseudomonas e Candida albicans, a infecção do trato respiratório é também bastante comum. Fatores como idade, patologia de base, instrumentação do trato respiratório, colonização da orofaringe com flora intestinal, é de suma importância atentar-se para a frequência nas unidades de terapia intensiva e em centros cirúrgicos, visto que nestes ambientes o paciente encontra-se debilitado e por vezes imunodeprimido, promovendo um ambiente propicio à proliferação das infecções. ${ }^{4}$

Os microrganismos apresentam-se no planeta em quantidade superior à de outros seres, sejam eles unicelulares (bactérias); pluricelulares (fungos) ou mesmo acelulares (vírus). Essa quantia de microrganismos deve-se à capacidade acelerada de reprodução e ao alto grau de adaptação às condições ambientais. Em específico as bactérias estão sujeitas a um processo denominado multirresistência bacteriana, o qual se dá tanto por uma capacidade intrínseca, quanto por aquisição de genes plasmidiais e por mutações em seu material genético. 0 uso indiscriminado de antibióticos contribui para essa resistência, pois exerce pressão seletiva sobre as bactérias. ${ }^{5}$

Após estudos tornou-se possível a compreensão de que para se evitar uma contaminação, faz-se fundamental o uso de equipamentos de proteção individual (EPI), a 
assepsia do ambiente; dos objetos que estiveram em contato com os pacientes, a higienização adequada por parte dos profissionais que o atende, bem como o isolamento do enfermo, caso a infecção seja potencialmente transmissível. ${ }^{2}$

Além disso, a educação da equipe, a consideração dos princípios de técnica cirúrgica e os cuidados pré-operatórios, a desinfecção e o manuseio correto dos equipamentos; as precauções padrão de higienização das mãos, o uso de luvas e aventais; a prevenção de broncoaspiração; o posicionamento adequado de cateteres e sacos coletores de diurese, bem como a observação da necessidade de troca dos mesmos, são algumas medidas preventivas de infecções hospitalares facilmente empregadas. Certo estudo brasileiro avaliou 332 pacientes em um hospital universitário, dentre os quais $61(18,6 \%)$ apresentaram infecção hospitalar. A taxa geral de mortalidade dos pacientes avaliados foi de 9,8\%; já a dos pacientes que tiveram óbito relacionado à infecção hospitalar foi de 22,3\%. Dessa forma, fica evidente que a população acometida com infecção hospitalar apresenta mortalidade maior que aquela não acometida. ${ }^{3}$

A Organização Mundial de Saúde (OMS) considera como aceitáveis taxas de infecção hospitalar até $5 \%$ ao ano, podendo variar de acordo com o porte do hospital. No Brasil, a Lei 9.431 de 6 de janeiro de 1997 obriga os hospitais a possuírem um programa de controle de complicações infecciosas hospitalares. A criação da Comissão de Controle de Infecção Hospitalar $(\mathrm{CClH})$ nas instituições hospitalares foi determinada pela Portaria 2.616/GM de 12 de maio de 1998. Tal serviço deve ser composto por representantes das áreas de enfermagem, medicina, farmácia, microbiologia e administração, visando controlar as complicações infecciosas por meio de vigilância epidemiológica, a fim de investigar surtos de infecções, implementar intervenções, bem como avaliar a eficácia das mesmas. ${ }^{6}$

O envelhecimento populacional constitui a mais importante mudança demográfica tanto em países desenvolvidos quanto em países em desenvolvimento, como o Brasil. A Organização Mundial da Saúde propõe 60 anos ou mais como idade em estudos da população idosa. $^{7}$

A hospitalização é considerada um risco para as pessoas idosas, por serem mais suscetíveis a infecções hospitalares causadas, muitas vezes, pelo repouso prolongado no leito durante o período de internação. Entre os fatores de risco para IH em idosos destacam-se: a presença de comorbidades; neoplasias; neutropenia; a utilização prévia de antimicrobianos; a estadia em unidade de terapia intensiva; a entubação traqueal por mais de 24 horas; a internação prolongada ou a transferência para outro hospital. Infecções do trato urinário, pneumonias, infecções do sítio cirúrgico e sepsis são as principais manifestações de infecção hospitalar em idosos. ${ }^{3}$

Uma importante consequência do envelhecimento populacional é o aumento de idosos com dependência e, consequentemente, com necessidade de institucionalização. Estima-se que 40\% das pessoas com 65 anos ou mais necessitarão de cuidados em uma instituição de longa permanência para idosos (ILPI) durante a sua vida. Em comparação a indivíduos jovens, os idosos apresentam diversos eventos que os predispõem à infecção, condição que aumenta a morbidade e mortalidade. O processo infeccioso é uma das mais 
frequentes causas de hospitalização e de morte em pacientes em ILPI. Levantamentos de prevalência de infecções em unidades geriátricas mostram que de $5 \%$ a $10 \%$ dos pacientes desenvolvem algum quadro no decorrer de um mês. ${ }^{7}$

Portanto, este estudo tem como objetivo identificar a prevalência de $\mathrm{IH}$ em idosos que ficaram internados na unidade de Clínica Médica de um hospital universitário nos anos de 2014 e 2015.

\section{MÉTODOS}

Trata-se de um estudo epidemiológico, de caráter descritivo correlacional, retrospectivo, com análise quantitativa de prontuários. Como afirmam Polit, Beck e Hungler (2001), na pesquisa retrospectiva, o investigador concentra-se em um resultado que ocorre na atualidade, estabelecendo os fatores antecedentes que tenham contribuído para a sua causa.

Além disso, a finalidade dos estudos descritivos correlacionais é observar, descrever e documentar aspectos de uma situação, de maneira que se ressalta a descrição dos relacionamentos entre as variáveis. Este tipo de pesquisa tem como vantagem a tendência de ser altamente realista, por tratar-se de um estudo epidemiológico; nessa perspectiva, a Epidemiologia, nos seus enfoques social e crítico é uma ciência fundamental para o provimento e interpretação de informações que possibilitem analisar fenômenos no contexto político-econômico-social em um determinado momento histórico; todavia a concretização das mudanças propostas depende das mentes e mãos envolvidas, assim como da interação destas com os demais processos sociais. ${ }^{8}$

A presente pesquisa foi realizada em um hospital universitário do Distrito Federal, no Serviço de Arquivo Médico (SAME).

Consideramos a amostragem não-probabilística, do tipo por conveniência. Como critério de inclusão foi considerado os seguintes aspectos: ser prontuário de pessoas idosas, ou seja, o paciente deveria ter 60 anos ou mais, ter ficado internado na unidade de internação da clínica médica em algum período dos anos de 2014 e 2015.

A coleta de dados foi realizada em uma única etapa, por meio do uso de um instrumento elaborado pelos pesquisadores (APÊNDICE A), através do qual as seguintes variáveis foram coletadas: idade do paciente; sexo; quadro clínico do cliente desde o momento em que este adentrou a unidade de internação até a sua alta; medicamentos utilizados pelo cliente na unidade de internação; exames realizados na unidade; suspeitas e comprovações diagnosticas referentes ao quadro clínico.

A análise dos dados, quantitativa, foi realizada por meio de distribuição e frequência absoluta e percentual, com a elaboração de tabelas, em uma planilha eletrônica que foi construída utilizando o programa Excel da plataforma Microsoft Windows. A análise dos dados foi realizada apenas pelos pesquisadores envolvidos.

A pesquisa foi aprovada pelo Comitê de Ética da Faculdade de Ciências da Saúde sob o número CAAE: 52861816.1.0000.0030, 09/03/2016. 
A amostra constitui de 102 prontuários no ano 2014 e 103 no ano de 2015, totalizando 205 prontuários, referentes às internações de pacientes na Clínica Médica, sendo destes $58,8 \%(n=57)$ no ano de 2014 e $34,9 \%(n=36)$ no ano de 2015 , no total $45,3 \%$ $(\mathrm{n}=93)$ de pessoas com 60 anos ou mais.

A taxa de IH no período de internação para estes idosos foi no total de $21,5 \%$.

Tabela 1. Distribuição do sexo, faixa etária e procedência de idosos internados na unidade de clínica médica do Hospital Universitário de Brasília durante os anos de 2014 e $2015(n=93)$

\begin{tabular}{lcc} 
Variável & N & \\
Sexo & 50 & $\%$ \\
\hline Feminino & 43 & $53,8 \%$ \\
Masculino & & $46,2 \%$ \\
\hline Faixa etária & 38 & \\
\hline 60 - 69 anos & 33 & $40,8 \%$ \\
70 - 79 anos & 18 & $35,5 \%$ \\
80 - 89 anos & 4 & $19,4 \%$ \\
90 - 99 anos & & $4,3 \%$ \\
\hline Procedência & 15 & \\
Brasília - DF & 59 & $16,1 \%$ \\
RAs - DF & 19 & $63,5 \%$ \\
Outras cidades - GO & & $20,4 \%$
\end{tabular}

Destaca-se que o gênero pouco influenciou nos admitidos com predominância do sexo feminino (53,8\%); a faixa etária teve uma boa divergência, mas aqueles com idade de 60 a 69 anos $(40,8 \%)$ foi o maior público dentre os idosos; também notamos que a grande maioria dos admitidos eram procedentes de regiões administrativas do próprio Distrito Federal $(63,5 \%)$ o que concluísse que a instituição estudada por ser um centro de ensino referência em diversas especialidades atende a uma margem de pacientes vasta e de distintas regiões.

Tabela 2. Distribuição dos Diagnósticos Médicos Admissão e Diagnósticos Médicos Alta dos idosos internados na unidade de clínica médica do Hospital Universitário de Brasília durante os anos de 2014 e 2015 (n=93)

\begin{tabular}{lcc} 
Variável & & \\
\hline Diagnósticos Médicos Admissão & $\mathbf{n}$ & $\%$ \\
\hline Sistema Cardiovascular & 12 & $13 \%$ \\
Sistema Respiratório & 21 & $22,6 \%$ \\
Sistema Digestório & 36 & $38,8 \%$ \\
Sistema Nervoso & 4 & $4,3 \%$ \\
Sistema Endócrino & 0 & $0 \%$ \\
Sistema Esquelético & 0 & $0 \%$ \\
Sistema Muscular & 1 & $1 \%$
\end{tabular}




\begin{tabular}{lcc}
\hline Sistema Imunológico & 5 & $5,3 \%$ \\
Sistema Linfático & 1 & $1 \%$ \\
Sistema Sensorial & 0 & $0 \%$ \\
Sistema Reprodutor & 3 & $3,2 \%$ \\
Sistema Tegumentar & 7 & $7,6 \%$ \\
Sistema Urinário & 3 & $3,2 \%$ \\
\hline Diagnósticos Médicos Alta & $\mathrm{n}$ & $\%$ \\
\hline Obitos & 25 & $26,8 \%$ \\
Melhora do quadro inicial & 36 & $38,8 \%$ \\
Inalterados & 32 & $34,4 \%$
\end{tabular}

É possível visualizar que os principais diagnósticos dos admitidos foram dos sistemas digestório (Câncer do trato gastrointestinal) (38,8\%) e respiratório (Pneumonias em geral) (22,6\%). A taxa geral de mortalidade dos pacientes avaliados foi de $(26,8 \%)$; já a dos pacientes que tiveram óbito relacionado à infecção hospitalar foi de $52 \%$. Dessa forma, fica evidente que a população acometida com infecção hospitalar apresenta mortalidade maior que aquela não acometida. Respectivamente está o quadro daqueles diagnósticos inalterados $(34,4 \%)$ que muitas das vezes são casos paliativos.

Tabela 3. Distribuição do tempo internação dos idosos na unidade de clínica médica do Hospital Universitário de Brasília durante os anos de 2014 e 2015 $(n=93)$

\begin{tabular}{lcc}
\hline Variável & & \\
\hline Tempo de Internação & N & $\%$ \\
\hline $01-10$ dias & 52 & $56 \%$ \\
$11-20$ dias & 26 & $28 \%$ \\
$21-30$ dias & 13 & $13,9 \%$ \\
$31-40$ dias & 2 & $2,1 \%$ \\
\hline
\end{tabular}

Em sua maioria o tempo de internação foi de 1 a 10 dias (56\%) o que mostra que a CM atende muitos casos com rápida melhora e também casos com programação diária para casos oncológicos (onde o admitido fica de 1 a 3 dias para realização da quimioterapia); em segundo temos aqueles com um período de 11 a 20 dias (28\%) que considero com grau de perigo maior para $\mathrm{IH}$ em relação ao dado passado, pois gera maior tempo de internação, mais procedimentos invasivos, maior manipulação do mesmo e gravidade do quadro aumentada.

Ainda durante a coleta, foi possível observar por meio das fichas do Centro de Controle de Infecção Hospitalar $(\mathrm{CCIH})$, identificar três micro-organismos multirresistentes, sendo eles: Streptococcus Agalactiae em 1,1\% dos prontuários do ano de 2014; Escherichia Coli com 1,1\% e Klebsiella pneumoniae em 1,1\% dos prontuários no ano de 2015. 
Pacientes idosos apresentam taxas elevadas de internação hospitalar e maior média de permanência na instituição de saúde, quando comparada à população de menor idade. É complexo afirmar que uma taxa de IH de $21,5 \%$ é baixa ou alta, pois a IH varia de acordo com o porte do hospital, tipo de assistência oferecida, o fato de ser um hospital de ensino, dentre outros. Em outro estudo divulgado em 2014, constatou-se uma taxa média mensal de $13,4 \%$ de IH entre idosos. Ainda em mais um estudo de 2006, a incidência foi de $18,17 \%$ em 100 admissões. ${ }^{3,9}$

Entretanto, é sabido que cerca de $1 / 3$ das IH podem ser evitadas. Para tanto, o CDC (Centro de Controle de Prevenção de Doenças) estabelece como medidas as precauções padrão e as baseadas nas vias de transmissão das doenças. As precauções padrão devem ser aplicadas com todos os pacientes e baseia-se na premissa de que a existência de barreira física, mecânica ou química entre os patógenos e o indivíduo bloqueia o ciclo de transmissão das doenças. As precauções baseadas nas vias de transmissão se aplicam aos doentes hospitalizados com doença infecciosa presumida ou confirmada, transmitidas pelo ar, por gotículas ou pelo contato. ${ }^{9}$

Durante a pesquisa percebemos que das pessoas acometidas por $\mathrm{IH}, 53 \%$ eram do sexo feminino. Estudo realizado em outro hospital universitário também revelou percentuais semelhantes de acometimento por IH relacionada ao sexo, com 49,2\% dos casos ocorrendo no sexo feminino e $50,8 \%$ no sexo masculino. Destaca-se também, a alta taxa de IH nas pessoas idosas (88,3\%). Em outro estudo realizado constatou-se que em pessoas acima de 60 anos o acometimento foi mais elevado que o presente estudo, com taxa de $38,4 \%$ dos casos de $\mathrm{IH}$ em idosos. ${ }^{10}$

Já o tempo médio de internação foi de 14 dias. Tomando como base outro estudo que referiu tempo médio de internação de 36 dias, o tempo médio de internação do presente estudo foi bem inferior ao aqui relatado. Isso pode estar relacionado com as doenças de base dos pacientes que adquiriram $\mathrm{IH}$, uma vez que a $\mathrm{CM}$ do Hospital mencionado é referência em tratamentos oncológicos, a patologia de base favorece a ocorrência da IH pois desestabiliza os mecanismos de defesa anti-infecciosa, devido ao seu tratamento agressivo, ocasionando desnutrição e déficit no sistema imunológico. ${ }^{10}$

A microbiota hospitalar mostrou-se composta por micro-organismos como: Streptococcus Agalactiae (Dentre os dez sorotipos conhecidos, este na classe do III é o mais encontrado nas doenças do neonato, principalmente meningite e sepse); Escherichia Coli (Principal agente encontrado em infecções do trato urinário), Klebsiella pneumoniae, principal agente encontrado em infecções do trato respiratório. No entanto, esses achados não puderam ser devidamente tabelados pela dificuldade na busca por resultados dos exames bacteriológicos. Mesmo assim, são micro-organismos que requer atenção, pois em pacientes idosos tendem a aumentar o período de internação, bem como, agravar seu diagnóstico médico de admissão, pois são mais comuns em grandes centros hospitalares. ${ }^{7,11}$

Os diagnósticos referentes ao sistema digestório foram as $\mathrm{IH}$ mais frequente e a menos frequente foram as do sistema endócrino respectivamente também as do sistema urinário. 0 mais preocupante é saber que foi uma taxa retirada de 93 prontuários de idosos, expondo assim a fatídica fragilidade da saúde do idoso que é mais propenso ao risco de 
infecções. Destaca-se que para o diagnóstico de enfermagem "Risco de infecção" as Intervenções de Enfermagem segundo aNIC (Nursing Interventions Classification) trazem 29 sugestões, entre elas está o promover banho diário, monitorizar fluídos e eletrólitos, promover a vacinação, controlar a exposição a doenças transmissíveis, oferecer aporte nutricional, observar diariamente os aspectos da pele e monitorizar sinais vitais. ${ }^{12,13}$

Durante a coleta foi dificultoso determinar alguma intervenção citada acima, ficando assim complexa a avaliação deste determinante. No entanto, é fato que as anotações nos prontuários muitas vezes não são encontradas e por ser um portuário físico sua vida útil se torna consideravelmente curta, devido a sua composição material e armazenagem o que impossibilita o discernimento de alguns dos dados coletados.

\section{CONSIDERAÇÕES FINAIS}

Uma vez o idoso adoecido e com necessidade de internação, é exposto aos riscos do ambiente hospitalar, devido ao processo de imunossenescência, às doenças crônicodegenerativas e a toda fisiologia do envelhecimento, se encontram mais suscetíveis às complicações infecciosas que acabam por estender o tempo de convalescença.

O que nos chamou a atenção foram as características extrínsecas e intrínsecas do paciente que podem estar relacionadas com o surgimento da $\mathrm{HH}$, a qual destacamos $\mathrm{O}$ período de tempo de internação (média de 7 dias a 34 dias), a idade (mínima de 60 anos) e os diagnósticos médicos. Os indicadores analisados durante a pesquisa podem favorecer uma análise que pode estabelecer ações de prevenção de IH por parte de todos os profissionais de saúde envolvidos no cuidado aos pacientes e, principalmente, aos próprios idosos, dos quais devem ser considerados todos os aspectos do processo de envelhecimento senil e senescente.

\section{REFERÊNCIAS}

1. Fontana, R. T. (2006). As infecções hospitalares e a evolução histórica das infecções. Rev. bras. enferm. [Internet]. 59(5). Outubro de 2006 - [acessado 06 de junho 2017]; 59 (5): 703-706. Disponível em: http: //www.scielo.br/scielo.php?script=sci_arttext\&pid=S003471672006000500021\&lng=en. http://dx.doi.org/10.1590/S0034-71672006000500021.

2. Queiroz N. Q. A resistência bacteriana no contexto da infecção hospitalar. Texto contexto - enferm. [Internet]. 2004 [citado 06 de junho 2017]; 13 (spe): 64-70. Disponível em http://www.scielo.br/scielo.php?script=sci_arttext\&pid=S010407072004000500007\&lng=en. http://dx.doi.org/10.1590/S0104-07072004000500007.

3. Izaias, É. M., Gomes, D. M. S., Rossaneis, M. Â., Belei, R. A. Custo e caracterização de infecção hospitalar em idosos. Ciênc. saúde coletiva [Internet]. Agosto de 2014 [citado 06 de junho 2017]; 19 (8): 3395-3402. Disponível em: http: // www.scielo.br/scielo.php?script=sci_arttext\&pid=S1413- 
4. Gonçalves, D. C., Kreutz, I., Lins J. F. A. B. A infecção hospitalar em Mato Grosso: desafios e perspectivas para a enfermagem. Texto contexto - enferm. [Internet]. 2004 [citado 06 de junho 2017]; 13(spe): 71-78. Disponível em: http: / / www.scielo.br/scielo.php?script=sci_arttext\&pid=S0104$\underline{07072004000500008 \& \text { lng }=e n}$. http: / / dx.doi.org/10.1590/S0104-07072004000500008.

5. Carvalho, R. H. D., Vieira, J. F., Gontijo-Filho, P. P., \& Ribas, R. M. (2010). Sepse, sepse grave e choque séptico: aspectos clínicos, epidemiológicos e prognóstico em pacientes de Unidade de Terapia Intensiva de um Hospital Universitário. Revista da Sociedade Brasileira de Medicina Tropical, 43(5), 591-3. - [acessado 27 de novembro de 2015]. Disponível em: http://www.scielo.br/pdf/rsbmt/v43n5/v43n5a25

6. Agência nacional de vigilância sanitária. Indicadores Nacionais De Infecções Relacionadas à Brasil: ANVISA, 2010. - [acessado 27 de novembro de 2015]. Disponível

em:

http: //portal.anvisa.gov.br/wps/wcm/connect/1ff4120047457e9b8a6ede3fbc4c6735 /INDICADORES+NACIONAIS+DE+INFEC\%C3\%87\%C3\%830+-+Setembro+2010++NOVO.pdf?MOD=AJPERES.

7. Villas-Bôas, P. J. F., Ruiz, T. Ocorrência de infecção hospitalar em idosos internados em hospital universitário. Rev. Saúde Pública [Internet]. Junho de 2014 [acessado 06 de junho 2017]; 38(3): 372-378. Disponível em:

http: / / www.scielo.br/scielo.php?script=sci_arttext\&pid=S003489102004000300006\&lng=en. http: //dx.doi.org/10.1590/S0034-89102004000300006.

8. Medeiros, A. R. P., Larocca, L. M., Chaves, M. M. N., Meier, M. J., Wall M. L. A epidemiologia como referencial teórico-metodológico no processo de trabalho do enfermeiro. Rev. esc. enferm. USP [Internet]. Dezembro de 2012 [citado 06 de junho 2017]; 46 (6): 1519-1523. Disponível em: http: / / www.scielo.br/scielo.php?script=sci_arttext\&pid=S0080-

$\underline{62342012000600032 \& l n g=e n}$. http: / / dx.doi.org/10.1590/S0080-62342012000600032.

9. Martins, P. "Epidemiologia das infecções hospitalares em centro de terapia intensiva de adulto." (2006) - [acessado em 11 novembro 2015], Disponível em: http: //www.bibliotecadigital.ufmg.br/dspace/handle/1843/ECJS-6XWQ8R

10. Nogueira, P. S. F., Moura, E. R. F., Costa, M. M. F., Monteiro, W. M. S., \& Brondi, L. (2009). Perfil da infecção hospitalar em um hospital universitário. Rev enferm UERJ, 17(1), 96-101. - [acessado em 11 novembro 2015], Disponível em: http: / /files.bvs.br/upload/S/0104-3552/2009/v17n1/a017.pdf

11. Fiolo, K., Zanardi, C.E., Salvadego, M., Bertuzzo, C. S., Amaral, E., Calil, R. Taxa de infecção e sorotipos de Streptococcus agalactiae em amostras de recém-nascidos infectados na cidade de Campinas (SP), Brasil. Rev. Bras. Ginecol. Obstet. [Internet]. Dezembro 2012 - [acessado 06 de junho 2017]; 34(12): 544-549. Disponível em: http://www.scielo.br/scielo.php?script=sci_arttext\&pid=S010072032012001200003\&lng=en. http: / / dx.doi.org/10.1590/S0100-72032012001200003.

12. Sakano, L. M., Yoshitome, A. Y. Diagnosis and nursing interventions on elderly inpatients. Acta paul. enferm. [Internet]. Dezembro de 2007 [citado 06 de junho 
2017]; 20

(4):

495-498.

Disponível

em:

http: //www.scielo.br/scielo.php?script=sci_arttext\&pid=S0103-

21002007000400018\&lng=en. http://dx.doi.org/10.1590/S0103-21002007000400018.

13. Villas-Bôas, P. J. F., Ferreira, A. L. A. Infecção em idosos internados em instituição de longa permanência. Rev. Assoc. Med. Bras. [Internet]. Abril de 2007 [citado 06 de junho 2017]; $53 \quad$ (2): 126-129. Disponível em: http: //www.scielo.br/scielo.php?script=sci_arttext\&pid=S0104-

$\underline{42302007000200016 \& l n g=e n} . \underline{\text { http://dx.doi.org/10.1590/S0104-42302007000200016. }}$. 
APÊNDICE - INSTRUMENTO DE COLETA DE DADOS

\begin{tabular}{|c|c|c|c|}
\hline \multicolumn{3}{|l|}{ Iniciais: } & $\mathrm{N}^{\circ}:$ \\
\hline \multicolumn{3}{|l|}{ Idade: } & Sexo: ( ) Feminino ( ) Masculino \\
\hline \multicolumn{3}{|l|}{ Naturalidade: } & Procedência: \\
\hline \multicolumn{3}{|c|}{ Data de Admissão: (dd/mm/aaaa) } & Data da alta: (dd/mm/aaaa) \\
\hline \multicolumn{4}{|c|}{ Especialidade Médica que internou: } \\
\hline \multicolumn{4}{|c|}{ Diagnósticos Médicos Admissão } \\
\hline \multicolumn{3}{|l|}{1.} & 2. \\
\hline \multicolumn{3}{|l|}{3.} & 4. \\
\hline \multicolumn{3}{|l|}{5.} & 6. \\
\hline \multicolumn{3}{|c|}{7.} & 8. \\
\hline \multicolumn{4}{|c|}{ Diagnósticos Médicos Alta: } \\
\hline \multicolumn{3}{|l|}{1.} & 2. \\
\hline \multicolumn{3}{|l|}{3.} & 4. \\
\hline \multicolumn{3}{|l|}{5.} & 6. \\
\hline \multicolumn{3}{|l|}{7.} & 8. \\
\hline \multicolumn{4}{|c|}{ Medicamentos utilizados na internação } \\
\hline \multicolumn{4}{|c|}{\begin{tabular}{l|l} 
Nome da droga & Via de administração
\end{tabular}} \\
\hline \multicolumn{4}{|l|}{1.} \\
\hline \multicolumn{4}{|l|}{2.} \\
\hline \multicolumn{4}{|l|}{3.} \\
\hline \multicolumn{4}{|l|}{4.} \\
\hline \multicolumn{4}{|l|}{5.} \\
\hline $\begin{array}{l}\text { Exames } \\
\text { solicitados }\end{array}$ & Data do exame & $\begin{array}{l}\text { Patógenos } \\
\text { identificados }\end{array}$ & Antibiograma \\
\hline \multicolumn{4}{|c|}{$\begin{array}{l}\text { Durante a internação fez uso de algum dispositivo médico invasivo? } \\
\text { Não ( ) Sim ( ) } \\
\text { Se sim, quais: (SNE, SNG, SVD, cateteres...) Especificar: }\end{array}$} \\
\hline
\end{tabular}




\section{ANEXO - APROVAÇÃO DO CEP}

\section{$\longrightarrow$ \\ Universidade de Brasília \\ Faculdade de Ciências da Saúde \\ Comitê de Ética em Pesquisa - CEP/FS \\ PROCESSO DE ANÁLISE DE PROJETO DE PESQUISA}

TÍTULO DO PROJETO: "AVALIAÇÃO DO PERFIL DE INFECÇÕES HOSPITALARES EM UM HOSPITAL UNIVERSITÁRIO DO DISTRITO FEDERAL"

PESQUISADORA RESPONSÁVEL: ANDREA MATHES FAUSTINO DATA DE ENTRADA: 29/01/2016

CAAE: 52861816.1.0000.0030

Com base na Resolução 466/12, do CNS/MS, que regulamenta a ética em pesquisa com seres humanos, o Comitê de Ética em Pesquisa com Seres Humanos da Faculdade de Ciências da Saúde da Universidade de Brasília, após análise dos aspectos éticos e do contexto técnico-científico, resolveu APROVAR o projeto intitulado "AVALIAÇÃO DO PERFIL DE INFECÇÕES HOSPITALARES EM UM HOSPITAL UNIVERSITÁRIO DO DISTRITO FEDERAL", Parecer no 1.438 .370 , em 9 de março de 2016.

Notifica-se o(a) pesquisador(a) responsável da obrigatoriedade da apresentação de relatório(s) semestral(ais) e relatório final sobre o desenvolvimento do projeto a contar da data de aprovação do projeto inicial.

Brasília, 11 de março de 2016.

$$
\begin{aligned}
& \text { Pavi Togashi } \\
& \text { Profa. Dra. Marie Togashi } \\
& \text { Coordenadora - CEP-FS/UnB }
\end{aligned}
$$

